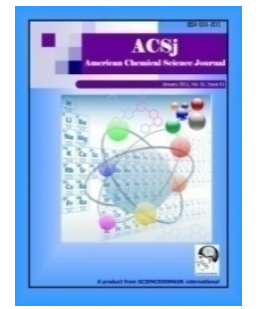

American Chemical Science Journal

3(1): 24-33, 2013

SCIENCEDOMAIN international

www.sciencedomain.org

\title{
Modified Composite Activated Carbon Derived from Post-Consumer Plastics and Lignocellulosic Materials
}

\author{
Abdoul Ntieche Rahman ${ }^{1,3}$, Loura Benguellah Benoît ${ }^{1}$, \\ Abdelaziz Bacaoui ${ }^{2}$ and Ketcha Joseph Mbadcam ${ }^{3^{3}}$ \\ ${ }^{1}$ University of Maroua, P.O Box 55, Maroua, Cameroon. \\ ${ }^{2}$ Department of Chemistry, University Caddy Ayyad, P.O Box 2390, Marrakech 40000. \\ Morocco. \\ ${ }^{3}$ Department of Inorganic Chemistry, University of Yaoundé I, P.O Box 812, Yaoundé,
}

Cameroon.

\section{Authors' contributions}

This work was carried out in collaboration between all authors. Authors $A N R$ and $A B$ designed the study, performed the statistical analysis. Author ANR wrote the protocol, and wrote the first draft of the manuscript. Authors LBB and KJM managed the analyses of the

study; author KJM corrected and performed the final manuscript. All authors read and approved the final manuscript.

Research Article

Received $11^{\text {th }}$ September 2012 Accepted $12^{\text {th }}$ November 2012 Published $10^{\text {th }}$ December 2012

\section{ABSTRACT}

The composite activated carbons were produced using both lignocellulosic materials and urban waste plastics and their characteristics were investigated. The mixture of raw material was first carbonized at $600^{\circ} \mathrm{C}$ in $\mathrm{N}_{2}$ atmosphere. The char obtained was then mixed with $\mathrm{KOH}$ (in the ratio 2:1 for $\mathrm{KOH} / \mathrm{char}$ ) before the activation process with steam at $850^{\circ} \mathrm{C}$. The results show that composite carbons are micro, mesoporous and have higher carbon yield compared to the carbons from both pure raw materials, which are mainly mesoporous. These results were confirmed by their high adsorption of methylene blue. BET surface area for all the samples were over the acceptable range (991.5 - 1412.9). Moreover, the average size of the pores of carbon between in the range of $1.8-2.3 \mathrm{~nm}$. Carbon surfaces were analyzed in detail using FTIR and SEM, exhibiting hydroxyl and

*Corresponding author: Email: jketcha@yahoo.com; 
carboxylic functional groups on the surfaces and cavities of mesopore size.

Keywords: Lignocellulosic materials and waste plastics; impregnation; composite activated carbon; mesoporous; yield.

\section{INTRODUCTION}

The production and utilization of activated carbon has increased for decades, especially in water treatment and in industrial applications such as in the extraction of metal ions, air handling, purification [1], the decoloration of food in the food industry and in the pharmaceutical industry [1-3]. This is because of high adsorption capacity of carbon for certain toxins and poisons, due to their porous structure and accessibility of their surface to combat certain types of bacterial ailments. In the last thirty years, activated carbons have been used as catalysts and as catalysts support [4-7]. Despite such features, the production of activated carbon on a large scale is limited due to their high production cost. Consequently, activated carbon is being replaced by cheap adsorbents in many industrial applications, despite their low removal efficiencies compared with those of AC. Over the last decade, many studies have been carried out on the development of low-cost adsorbents derived from waste materials. So AC production costs have been reduced by choosing cheap and locally available raw materials such as urban wastes and agricultural wastes instead of costly deforestation [8].

A post-consumer plastic waste, with its wide commercial applications and low biodegradability, represents a serious challenge for developing countries. The transformation of post-consumer plastics into activated carbon appears not only as an alternative solution to the problems of pollution by plastics, but also a way of recycling it. Much work has recently been done on the preparation of AC from plastics, and the results have shown that they have a better adsorption capacity and a larger surface area as compared to those from lignocellulosic materials which are widely used on a commercial scale [9-13]. But the main problem here is that of low yield, as large quantities of plastic are needed to obtain a high yield. It is then very expensive compared to AC obtained from plant origins which have a relatively high output.

The present work is focused on the preparation of composite activated carbon from postconsumer plastics (polyethyleneterephtalate) mixed with lignocellulosic material (oil palm shell). It is hope that, this will increase the yield of AC compared to that from plastics waste only. For this purpose physical and chemical activation will be combined using steam vapor and $\mathrm{KOH}$ to increase their porosity.

\section{EXPERIMENTS}

\subsection{Raw Materials and Sample Preparation}

The raw materials for the preparation of ACs are synthetic plastic and Oil Palm Shell (OPS), as lignocellulosic materials. The composites ACs were obtained by mixing both PET and OPS in the ratios $2: 1$ and $1: 1$ respectively.

Oil palm shells (OPS) were granulated into particle sizes ranging from 0.5 to $1.5 \mathrm{~mm}$ in diameter and Polyethylenterephtalate (PET) samples were sliced into similar particles sizes. 
OPS and PET were mixed in the ratios 2:1 and 1:1 respectively, the mixtures were dried in the oven at $110^{\circ} \mathrm{C}$ and then, subjected to carbonization using a cylindrical furnace. The heating started from room temperature with a heating rate of $10^{\circ} \mathrm{C} / \mathrm{min}$ up to the final temperature of $600^{\circ} \mathrm{C}$. The heating process was stabilized with nitrogen at a flow rate of about $100 \mathrm{~mL} / \mathrm{min}$. The residence time of the samples at the final stabilized temperature of $600^{\circ} \mathrm{C}$ was $3 \mathrm{hrs}$. After heat treatment, the nitrogen flow was stopped and the charcoals were cooled down to room temperature.

Before the activation step, 5-6g of the carbonized samples were mixed with Potassium hydroxyl in the ratio $1: 2(\mathrm{char} / \mathrm{KOH})$ and dried in the oven overnight at $110^{\circ} \mathrm{C}$. The mixtures were activated with steam $(0,13 \mathrm{~mL} / \mathrm{min})$ in a furnace by heating the reactor from room temperature to $850^{\circ} \mathrm{C}$ at a heating rate of $10^{\circ} \mathrm{C} / \mathrm{min}$, with a residence time of $2 \mathrm{hrs}$. After the activation, the steam flow was stopped and the obtained ACs were cooled down to room temperature and washed with distilled water to a $\mathrm{pH}$ of 7 . For comparisons, activated carbons were also prepared from the pure raw materials (PET and OPS) in the cylindrical furnace under the same conditions (Fig. 1).

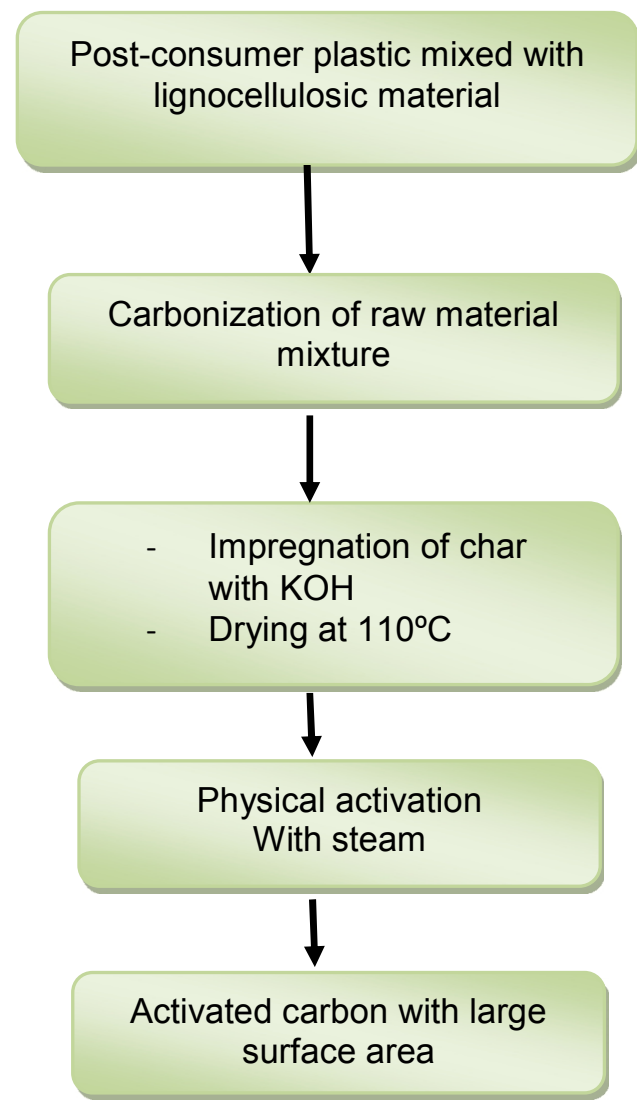

Fig. 1. The procedure for preparing composite activated carbon from post-consumer plastic and lignocellulosic material mixture 


\subsection{Characterization of Activated Carbons by Nitrogen Gas Adsorption}

Adsorption of gases at low temperature provides considerable information on the determination of specific surface area and pore size distribution of nanoporous adsorbents. Within the framework of this work, carbon samples were characterized for their surface and pore characteristics using an adsorption apparatus (Micromeritics TriStar surface Area and porosity analyzer). Analyses of adsorption and desorption of nitrogen were conducted at $195.8^{\circ} \mathrm{C}$. Before the experiments, the sample was degassed at $200^{\circ} \mathrm{C}$ overnight. Total surface areas were determined by applying the BET equation [13]. External surface areas were determined by applying the $t$-plot model between the range 7-9 $A^{\circ}$ [15]. Pore size distributions were determined using both BJH methods.

\subsection{Aqueous Adsorption Characteristics}

\subsection{1 lodine number}

The iodine number was determined by using the sodium thiosulfate volumetric method. Standard iodine solution was added over activated carbon (10 $\mathrm{mg})$ and after an equilibration time of $4 \mathrm{~h}$, the residual iodine concentration was determined by titration with standard sodium thiosulfate using starch as an indicator. The iodine number was defined as the adsorbed quantities of iodine (in mol gi of carbon) obtained by subtracting the residual concentration at equilibrium $\mathrm{Ce}$, from the initial concentration Co.

$$
Q_{o}=\frac{C_{o}-C_{e}}{m} V
$$

Where $\mathrm{m}$ and $\mathrm{V}$ are the mass of $\mathrm{AC}$ sample and the volume of adsorbing solution respectively.

\subsubsection{Methylene blue adsorption test}

The samples of carbons were investigated for their aqueous adsorption of dyes using methylene blue. Carbon samples $(10 \mathrm{mg})$ were mixed with $\mathrm{MB}$ in $100 \mathrm{~mL}$ stoppered Erlenmeyer flasks. Batch experiments were carried out in the shaker $(200 \mathrm{rpm})$ at room temperature for $4 \mathrm{~h}$. The solutions were filtered and the concentrations of solutions were then determined by spectrophotometer at $660 \mathrm{~nm}$. Then the quantity adsorbed was also calculated ( $\mathrm{mol} \mathrm{g}^{-1}$ of carbon) using equation 1.

\subsection{Scanning Electron Microscopy and Infra-Red analysis}

The carbon samples were analyzed using FTIR spectroscopy. The samples were mixed with potassium bromide and the mixture was pressed into pellets to be used in the analysis. The spectra were recorded from 4000 to $400 \mathrm{~cm}^{-1}$. Microstructures of the samples were examined using a Scanning Electron Microscope.

\section{RESULTS AND DISCUSSION}

The sample obtained from the mixture of raw materials are COM1I and COM2I respectively ratio 1:1 and 2:1 (PET/OPS), those obtained from polyethyleneterephtalate and oil palm 
shell are called PETI and MOPS respectively. The process for the preparation of the composite adsorbent is presented in Fig. 1. The characteristics of prepared carbon samples are presented in Table 1.

Table 1. Characteristics of different ACs obtained

\begin{tabular}{llll}
\hline Activated carbons & Raw materials & $\begin{array}{l}\text { Yields\% } \\
\text { Carbonization }\end{array}$ & Activation \\
\hline OPS & Oil palm shell(OPS) & 30 & 45.7 \\
PETA & PET & 15 & 33.3 \\
COM1 & OPS +PET; ratio 1/1 & 24 & 58.7 \\
COM2 & OPS +PET; ratio 2/1 & 21 & 40.7 \\
\hline
\end{tabular}

\subsection{Nitrogen Adsorption Isotherms Pore Size Distributions}

The $\mathrm{N}_{2}$ adsorption isotherms at $77 \mathrm{~K}$ for the composite activated carbons produced from the mixture of post-consume plastics and lignocellulosic materials by phisico-chemical activation are presented in Fig. 2. All the samples gave type II isotherms, characteristic of microporous and mesoporous solids. The adsorption isotherms show adsorption-desorption hysteresis, indicating the presence of mesopores. Besides contributing significantly to the adsorption of the adsorbate, Mesoporous predominance could be attributed to the interaction of functional groups at the surface of char which favors the evolution of molecules during the heating process of activation, then probably creating external pores. These pores act as conduits leading the adsorbate molecules to the micropore cavity [16]. The impregnation of char by $\mathrm{KOH}$ generates a large external surface area for samples MOPS and MPET compared to their internal surface (micropores surface area). Although the micropores surfaces of composites ACs are greater than external surface, it can be noticed that the amount of their external surface are significant, in the case of COM2I where micropores and external surface are 570.3 and 514.7 respectively. The overall porosity development determined by $\mathrm{N}_{2}$ adsorption at $77 \mathrm{~K}$ using BET and BJH methods are shown in Table 2. It shows that all the samples have a large surface area between 1000 and $1500 \mathrm{~m}^{2} / \mathrm{g}$ with highly developed microporosity. The mesopore accumulate in a small size range (around 2-4 $\mathrm{nm}$ ) and this is more clearly seen in the MOPS and MPET samples. In the micropore size distributions, only COM1I sample showed an important amount of micropore below $1 \mathrm{~nm}$. Mesoporous predominance could be attributed to the interaction of functional groups at the surface of char which favors the evolution of molecules during the heating process of activation, then probably creating external pores. 


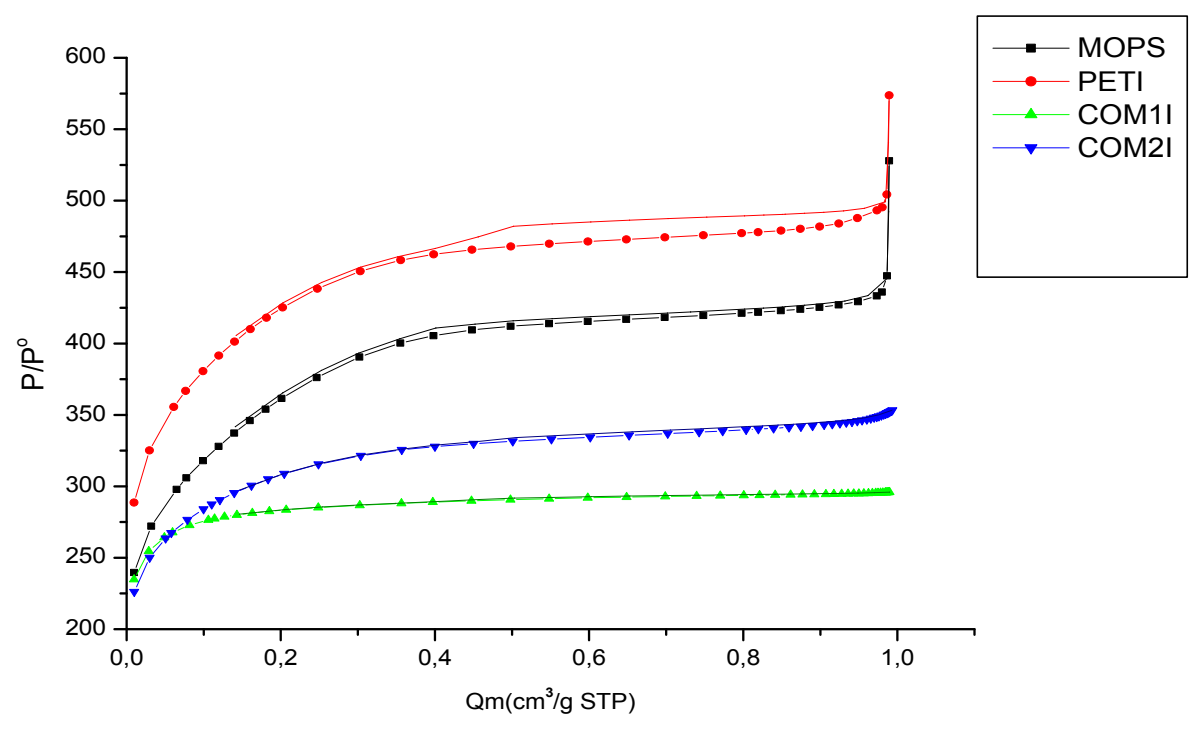

Fig. 2. Typical nitrogen adsorption/desorption isotherm of the four samples of activated carbon prepared by physical activation

Table 2. Porous parameters of the activated carbons

\begin{tabular}{|c|c|c|c|c|c|c|c|c|}
\hline \multirow[t]{2}{*}{ Samples } & \multirow[t]{2}{*}{$\begin{array}{l}S_{\text {BET }} \\
\left(M^{2} / G\right)\end{array}$} & \multirow[t]{2}{*}{$\begin{array}{l}S_{M 1} \\
\left(M^{2} / G\right)\end{array}$} & \multirow[t]{2}{*}{$\begin{array}{l}S_{E^{2}} \\
\left(M^{2} / G\right)\end{array}$} & \multicolumn{2}{|c|}{$\begin{array}{l}\text { Pores } \\
\text { volumes }\left(\mathrm{CM}^{3} / \mathrm{G}\right)\end{array}$} & \multicolumn{3}{|c|}{ Average pores sizes (NM) } \\
\hline & & & & $\mathbf{V}_{\text {MICRO }}$ & $\mathbf{v}_{\text {cum }}$ & BET ${ }_{\text {ADS }}$ & BJH $_{\text {DES }}$ & $\mathrm{BJH}_{\mathrm{ADS}}$ \\
\hline MOPS & 1221.7 & 312.6 & 909.1 & 0.1602 & 0.4909 & 2.2655 & 3.7693 & 3.7441 \\
\hline PETI & 1412.9 & 516.7 & 896.1 & 0.2634 & 0.4553 & 2.2085 & 3.7252 & 3.6253 \\
\hline COM1I & 991.45 & 829.93 & 161.52 & 0.3674 & 0.4574 & 1.8453 & 2.8920 & 2.8846 \\
\hline COM2I & 1085.0 & 570.26 & 514.7 & 0.2507 & 0.5439 & 2.0053 & 2.8875 & 2.9176 \\
\hline
\end{tabular}

\subsection{Adsorption Tests in Aqueous Solution}

Aqueous adsorption tests were conducted on the four adsorbates compounds with the aim of confirming their porous structure and also to test the adsorption capacity of inorganic and organic species from the aqueous phase. With regards to gas adsorption results, the samples are expected to adsorb higher quantities of methylene blue due to their large external area. Methylene blue is adsorbed by filling mechanisms due to the large amount of mesopores and adsorption by iodine proceeds by capillary condensation in the mesoporosity. Indeed the high adsorption capacity of methylene (between 350 at $525 \mathrm{~mol} / \mathrm{g}$ ) was found compared to the adsorption of iodine (300 - $420 \mathrm{~mol} / \mathrm{g})$, Fig. 3 [17]. Adsorption of methylene blue for COM2I sample is lower than that of the other samples, this can be justified by the fact that it contains micropores and mesopores, so the existing mesopores at the external surface is lower and serves only as the entrance to micropores. 


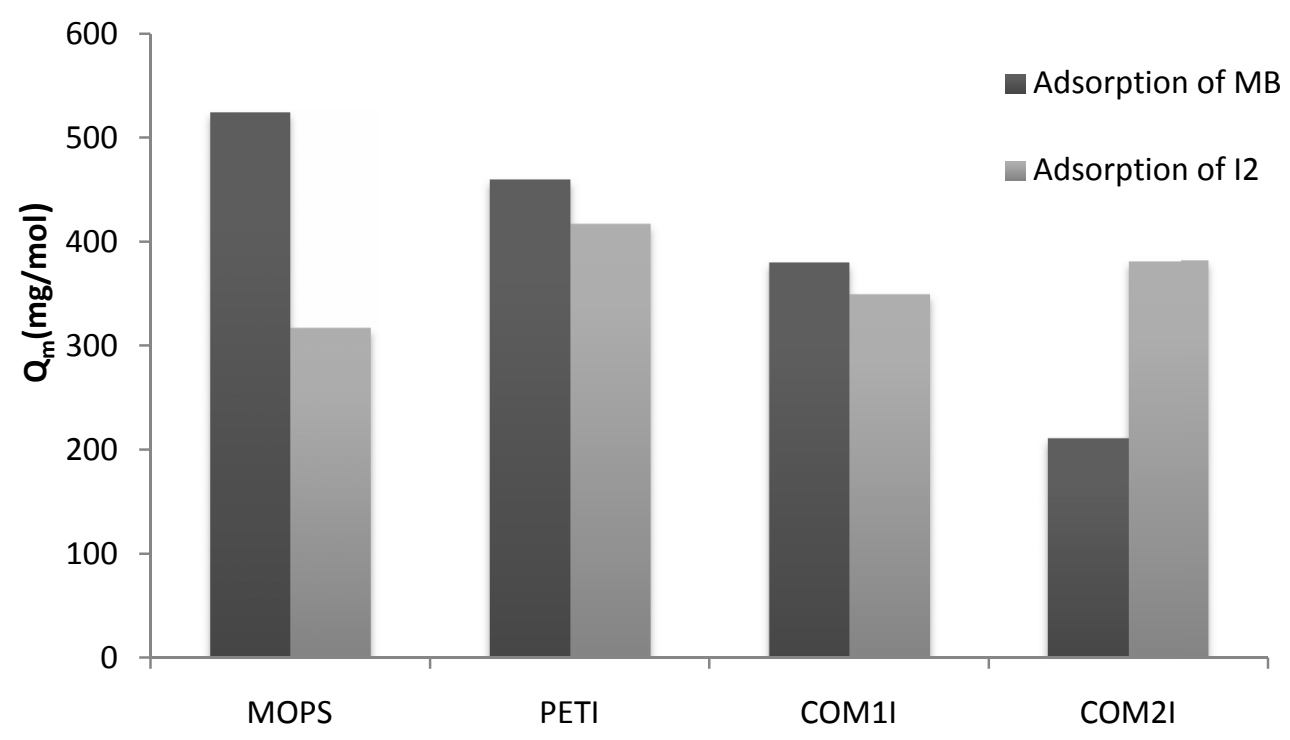

Fig. 3. Adsorption of methylene blue and iodine

\subsection{Surface Chemical and Morphologic Characteristics}

Infrared spectroscopy (IR) (Fig.4) is an important and forceful tool that can provide useful information about surface functional groups on carbons. The adsorption capacity of active carbons is determined by their physical or porous structure but is strongly influenced by the chemical structure [18-19]. The spectra show a weaker shoulder between 1550 at $1600 \mathrm{~cm}^{-1}$ which can be attributed to $\mathrm{C}=\mathrm{C}$ aromatics cycles stretching vibration. The dominant absorption peak around $1120 \mathrm{~cm}^{-1}$ indicated the existence of $\mathrm{C}=\mathrm{O}$ bond stretch. The region between 501 and $600 \mathrm{~cm}^{-1}$ for all the samples are due to deformation vibrations out of the aromatic $\mathrm{C}-\mathrm{H}$ bonds. The intense absorption band at $3400 \mathrm{~cm}^{-1}$ was attributed to absorbed water. It can be noticed in the spectra that the peaks appear at the same frequency but their intensity vary with sample showing that functional structure on the carbons are identical. The Scanning Electron Microscopy is used for imaging the morphologies of ACs. Examination of these carbons (Fig. 5) exhibit external surface structure indicating that in some parts of the carbon impregnation has produced cavities of mesopores size [20-21]. 


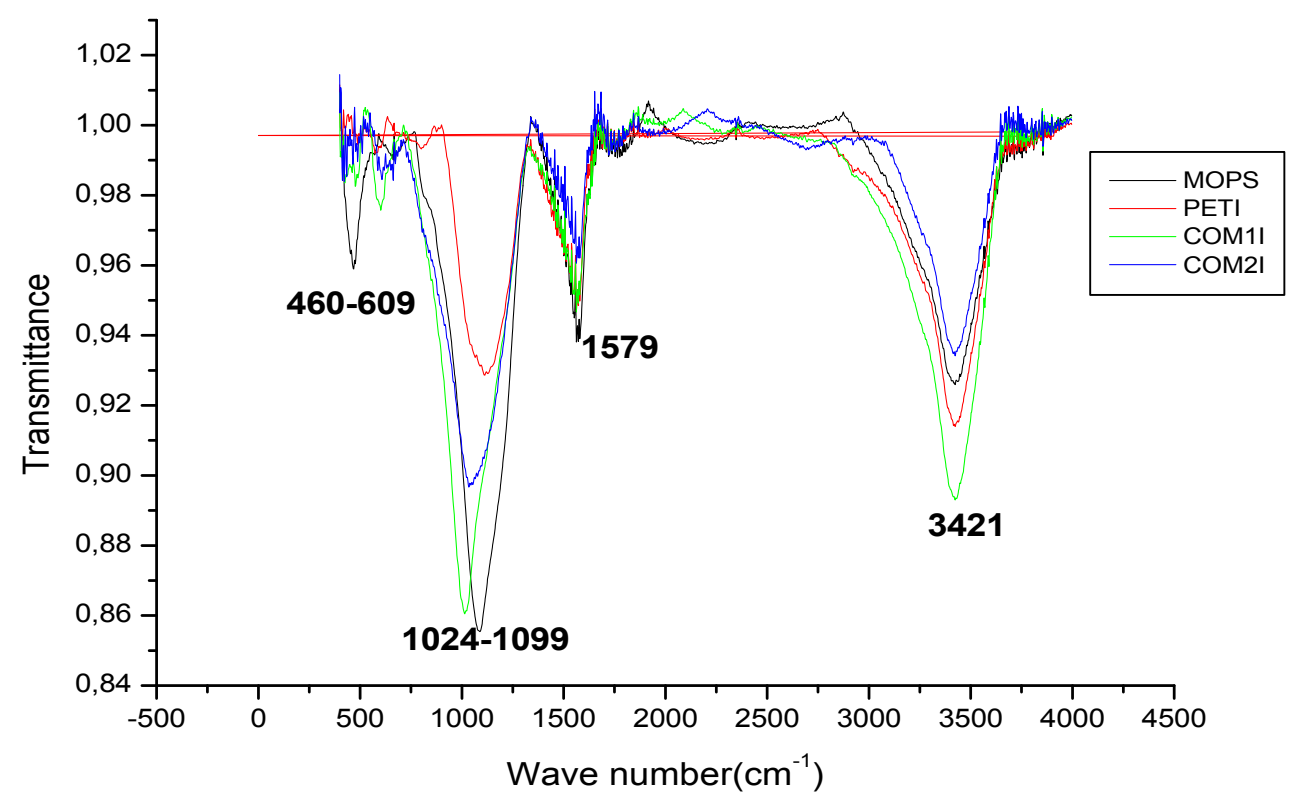

Fig. 4. FTIR spectra of four activated carbons obtained by physical activation
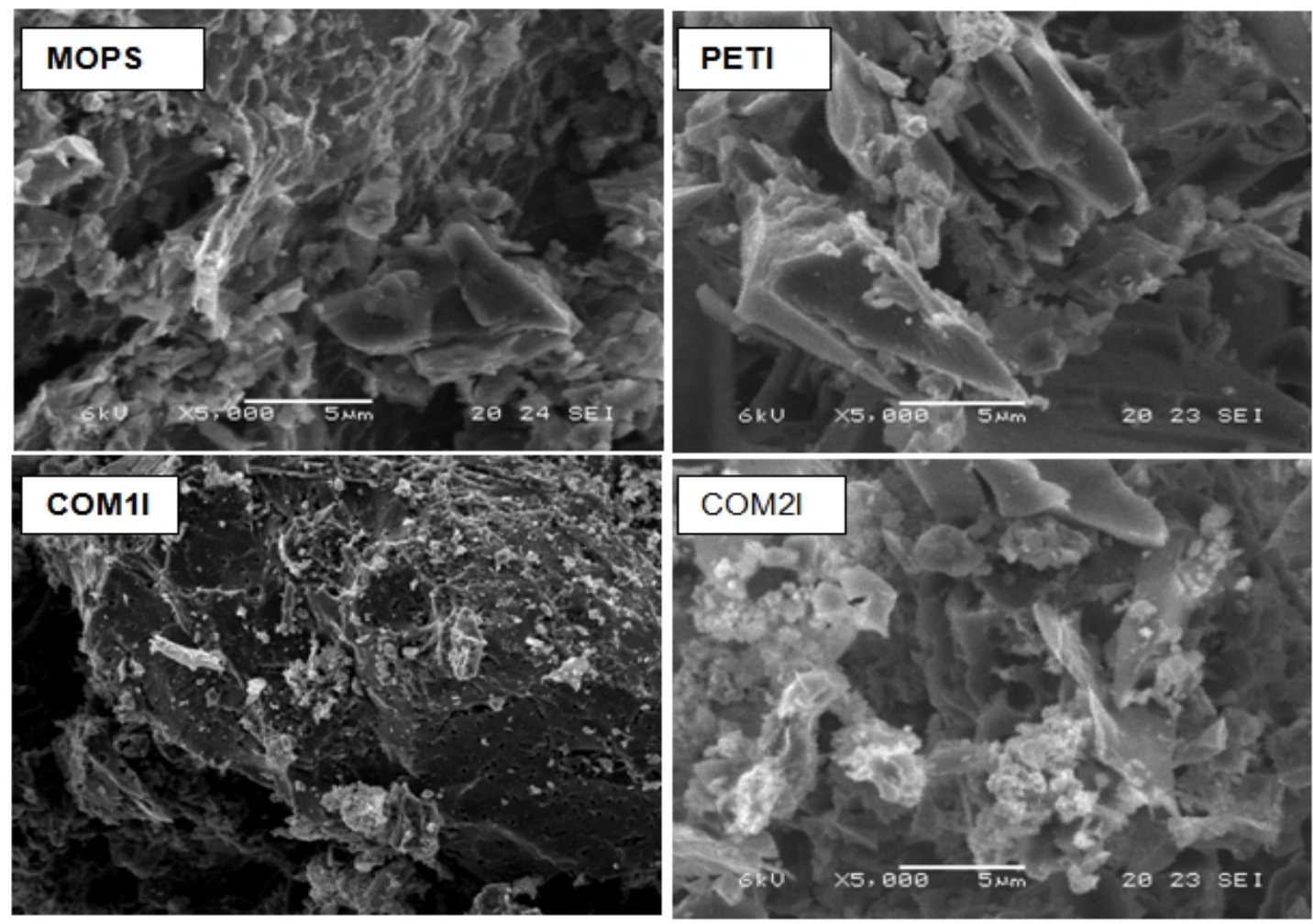

Fig. 5. SEM photographs of the four activated carbons prepared 


\section{CONCLUSION}

Activated carbons with high surface area can be produced by physico-chemical activation from a mixture of both waste lignocellulosic material and post-consumer plastics using $\mathrm{KOH}$ for impregnation. They have high methylene blue numbers compared to the adsorption of iodine. As revealed above, impregnation of char by $\mathrm{KOH}$ before activation contributed a significant influence on development of mesopores into the Composite adsorbent. The yield of composite ACs (24 and $21 \%$ for COM1I and COM2I respectively) is higher compared to the sample prepared from plastics (15\%). Using low energy conditions of preparation, the specific area of the entire samples were over the acceptable range $\left(991.45-1412.9 \mathrm{~m}^{2} / \mathrm{g}\right)$. Moreover, the size of the pores on the pore wall of the carbon is in the range of $1.8-2.3 \mathrm{~nm}$. Hydroxyl and carboxylic functional groups on the surfaces and cavities of mesopores size were also found at the adsorbent surface using FTIR and SEM analysis. Therefore, the composite ACs prepared developed porous adsorbents with a greater adsorption capacity; hence they can be used as low-cost adsorbent and as an alternative for environmental pollution remediation.

\section{ACKNOWLEDGEMENTS}

The authors are grateful to Professor A. Yaacoubi and the Laboratory of Applied Organic Chemistry, Faculty of Science, University Caddy Ayyad of Marrakech in Morocco, for accepting me to complete this work.

\section{COMPETING INTERESTS}

Authors have declared that no competing interests exist.

\section{REFERENCES}

1. Kushwah SK, Malik S, Singh A. Water quality assessment of raw sewage and final treated water with special reference to waste water treatment plant Bhopal, MP, India. Res. J. Recent. Sci. 2012;1(ISC-2011):185-190.

2. Theivarasu C, Mylsamy S, Sivakumar N. Adsorptive removal of crystal violet dye using agricultural waste cocoa (Theobroma cocoa) shell. Res. J. Chem. Sci. 2011;1(7):3845.

3. Vaishnav V, Daga K, Chandra S, Lal M. Adsorption studies of Zinc (II) ions using calotropis procera as an adsorbent. Res. J. Recent. Sci. 2012;1(ISC-2011):160-165.

4. Bhise RM, Patil AA, Raskar AR, Patil PJ, Deshpande D P. Removal of color of spent wash by activated charcoal adsorption and electrocoagulation. Res. J. Recent. Sci. 2012;1(6):66-69.

5. Rodrigues-Reinoso F. Introduction to Carbon Technologies. Publicaciones de la Universidad de Alicante, Spain. 1997.

6. Wrench J, Origin J. of the American Oil Chemists' Society. 2007;8(12):441-453.

7. Bansal RC, Donnet JB, Stoeckli F. In: Active Carbon. Marcel Dekker, New York; 1988.

8. Dias JM, Alvim-Ferraz MCM, Almeida MF, Rivera-Utrilla J, Sanchez-Polo M. Journal of Environmental Management. 2007;85:833-846. 
9. Krisztina L, Attila B, Lajos GN. Comparative adsorption study on carbon from polymer precursors. Carbon. 2000;38:1965.

10. Parra JB, Ania CO, Arenillas A, Rubiera F, Palacios JM, Pis JJ. Textural development and hydrogen adsorption of carbon materials from PET waste. J. Alloys Compd. 2004;379:280.

11. Parra JB, Ania CO, Arenillas A, Rubiera F, Pis JJ, Palacios JM. Structural changes in polyethylene terephthalate (PET) waste materials caused by pyrolysis and $\mathrm{CO}_{2}$ activation. Adsorp. Sci. Technol. 2006;24:439-450.

12. Kartel MT, Sych NV, Tsyba MM, Strelko VV. Preparation of porous carbons by chemical activation of polyethyleneterephthalate. Carbon. 2006;44:1013.

13. Ania CO, Cabal B, Parra JB, Pis JJ. Importance of the hydrophobic character of activated carbons on the removal of naphthalene from the aqueous phase, Adsorpt. Sci.; 2007.

14. Brunauer S, Emmett PH, Teller E. Adsorption of gases in multimolecular layers. J Am Chem Soc. 1938;60(3):309-19.

15. Lippens $\mathrm{BC}$, deBoer $\mathrm{JH}$, Studies on pore systems in catalysts $\mathrm{V}$. The t-plot method. J. Catal. 1965;4:319-23.

16. Bansal RC, Meenakshi G. Activated carbon adsorption. CRC Press. 2005;85-91.

17. Faust SD, Aly OM. Adsorption processes for water treatment, London: Butterworths. 1987;1-59.

18. Harry M, Rodriguez-Reinoso F. Activated Carbon, Elsevier Science \& Technology Books. 2006.

19. Kaneko K. Determination of pore size and pore size distribution. Adsorbents and catalysts. J Memb Sci. 1994;96:59-89

20. Bansal RC, Donnet JB, Stoeckli F. In: Active Carbon. Marcel Dekker, New York. 1988.

21. Gregg SJ, Sing KSW. Adsorption, surface area and porosity, Academic Press. London; 1982.

(C) 2013 Rahman et al.; This is an Open Access article distributed under the terms of the Creative Commons Attribution License (http://creativecommons.org/licenses/by/3.0), which permits unrestricted use, distribution, and reproduction in any medium, provided the original work is properly cited.

Peer-review history:

The peer review history for this paper can be accessed here: http://www.sciencedomain.org/review-history.php?iid=157\&id=16\&aid=717 